\title{
Fault Determination and Analysis of Complex Switching Structure at Multilevel Inverter
}

\author{
Erol CAN
}

Abstract: In energy conversion studies, some situations have been aimed at up to now. According to this, while the direct voltage is converted from some renewable energy sources to the alternating voltage, the shape of the voltage must be close to the sinus. Therefore, the works are being done on inverters with multi-levels. As the level of the inverters increases, the number of switches and control signals on them increases and it becomes harder to find the possible errors. Finding faults of a device with a large number of transistors with control signals is important, very difficult, and time-consuming task. This paper addresses the issue of determining fault conditions for a multi-level inverter with a very complex switching scheme. The results are analyzed and evaluated after the values obtained in the simulation are validated by the experimental study. For different switch fault conditions at the applications, the harmonic distortion of the alternating voltage is measured and made into tables. After that, different fault conditions of the 21-level inverter structure are explained when fault curves are created from the distortion value of the fault signals.

Keywords: complex switching; fault detection index; 21-level inverter

\section{INTRODUCTION}

The use of direct current sources in driving a device is limited. But, it is quite common and desirable to obtain direct current energy from renewable sources [1,2]. This direct current energy source needs to be transformed for using it more widely in electronic applications [3-7]. Therefore, multi-level inverters are used to obtain a good sine wave for the alternating voltage [7-10]. As the level of the inverter level increases, the number of switches and the number of signals controlling the switches also increases, so the circuit structure becomes complicated. That makes it difficult to detect a fault in the circuit structure. The switches are disabled in overheating; the operation of the voltages above the voltage values is allowed by the switch, and in the event of faults to the processor legs controlling the switches. In which case some of the switches do not work and therefore a faulty alternating voltage is generated. This work is different from other studies [1115] because it deals with switch and signal faults that can occur in a multi-level inverter as 21- level while creating the distortion index. The inverter structure to be diagnosed has twenty semiconductor switches and is controlled by sinus pulse width modulation. The pulse width is generated by intersecting ten triangular signals with a sinusoidal signal. The inverter structure and control system is built at Matlab Simulink and experimentation, and then run for different fault conditions. There may be a large number of possible fault conditions. However, the deterioration index curve, which gives information about what the deterioration tendencies are in the event of a fault is obtained for several different situations.

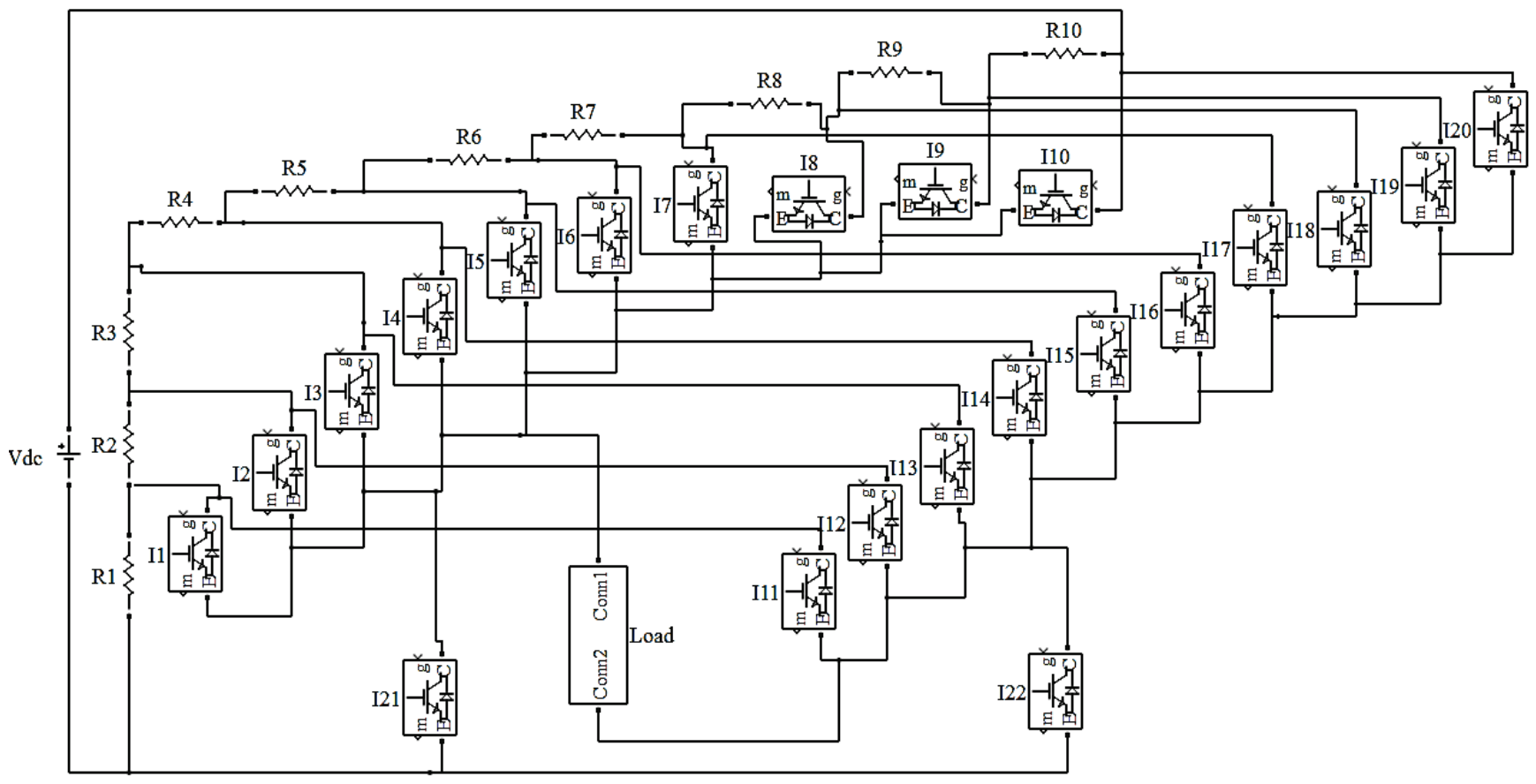

Figure 121-level inverter for fault detection

At the simulation and experimentation, the distortion value of the fault signal is measured. Then, the detection index of fault curve and figure is formed by the distortion value of faultless signal subtracting from the distortion 
value of the fault signal. The increase in the negative direction on the index curve shows the extra deterioration values due to the faults occurring on the device while the positive increases indicate the deterioration values that occur when the device is not faulty. So, Maps of defects that occur in the complex device structure are revealed. The detection of the faulty part and the control signal according to the obtained results is made with certainty because every faulty condition has its own unique characteristic curve. The simulation results are validated by the experimental results. The direction of the curves is negative, according to the current position of the element in which the fault occurs. The directions in the curves are positive when the fault does not arise. In this case, the detection of the faults occurring in a device with a very complex switches structure is facilitated. Thus, while the defective element is found in a short time without performing control of each individual element, it does not perform unnecessary operations on the other non-defective circuit elements. So deformations are prevented in the circuit.

\section{INVERTER STRUCTURE TO BE DIAGNOSED}

The inverter circuit in Fig. 1 is given for the fault detection and the distortion indexing of a complex device structure. There are resistances from $\mathrm{R} 1$ to $\mathrm{R} 10$ in order to divide the direct voltage supply on this inverter. There are 22 semiconductor IGBT switches to generate 21-level voltage. For experimentation, controller is dspace 1104, IGBT Switches are IRGB4055PbF, Source voltage $V_{\mathrm{dc}} 175$ $\mathrm{V}$, and load is resistive $(\mathrm{R})$ and inductive $(\mathrm{L})$ in series that is $100+j \cdot 0.001$. The voltage on the load appears as shown in Fig. 2 if there is no fault on the device.

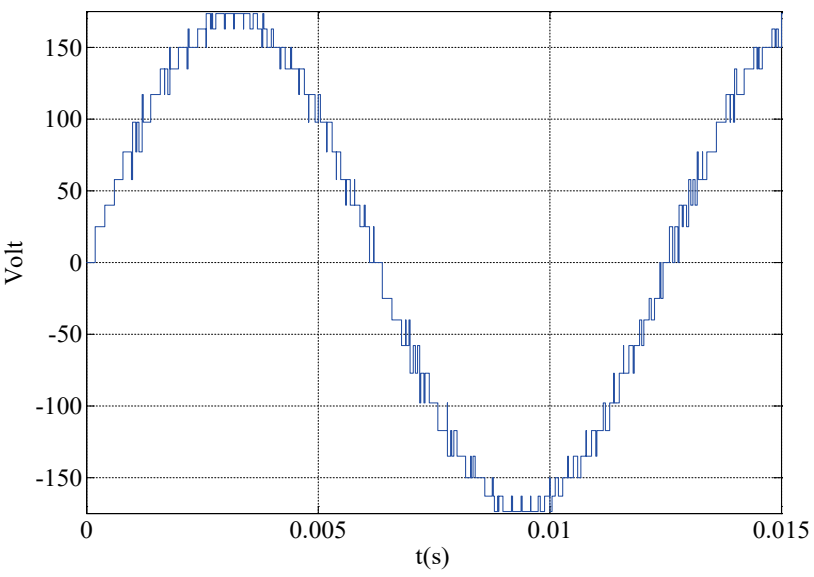

Figure 2 21- Level faultless voltage

The voltage with a frequency of $80 \mathrm{~Hz}$ has a 21-step voltage because all of the switches forming all the voltage levels on the load operate fully. This voltage peak is at 170 $\mathrm{V}$, which is $U_{\mathrm{m}}$. The created voltage $U(t)$ can be expressed as in Eq. (1).

$$
U(t)=10 U \cdot \sin (\omega t)
$$

For simulation and experimentation, the alternating voltage on the load will be as shown in Fig. 3 if faults occur in switches I1 1 and I12.
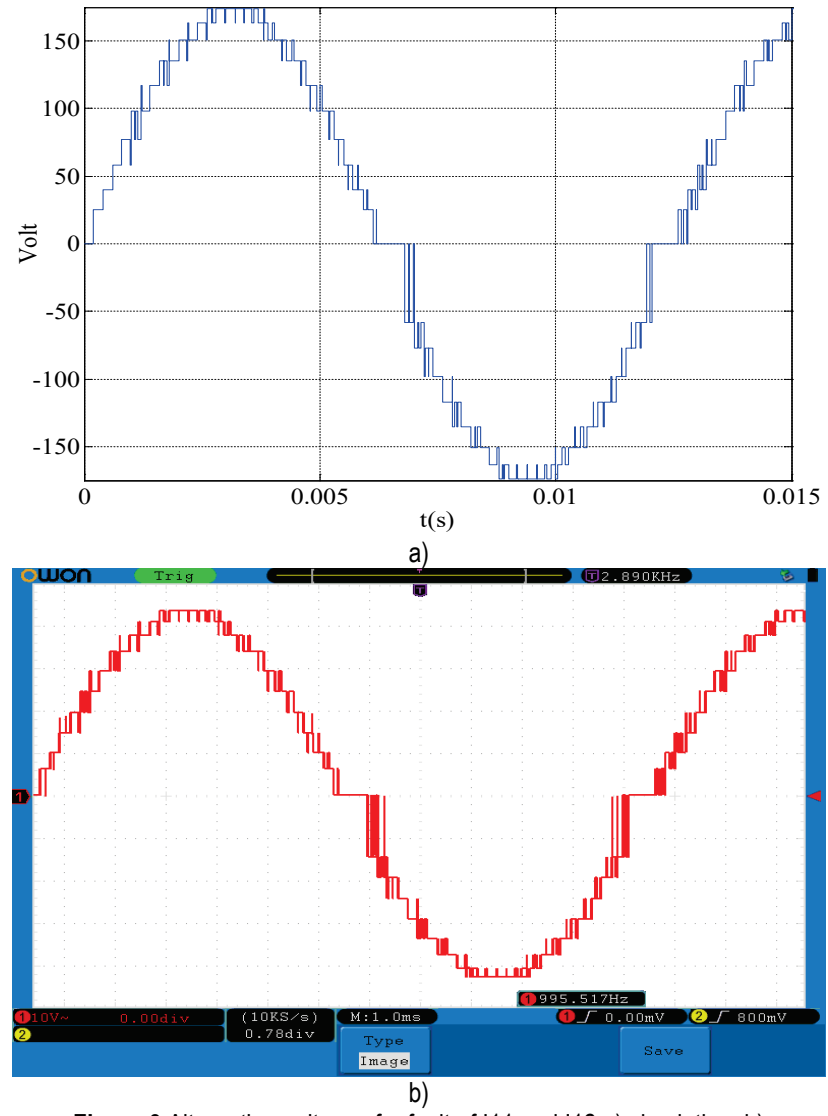

Figure 3 Alternating voltages for fault of I11 and I12 a) simulation, b) experimentation

The inability to operate these switches causes the two level steps to be lost in the negative part of the alternating voltage and that disrupts the effective value of the voltage in simulation and experimentation. $H_{0}$ is harmonic distortion of the voltage generated by the errorless device on the load; $H_{1}$ is harmonic distortion of the voltage generated by the faulty device on the load. The differences between these two values provide the distortion index $\left(D_{\mathrm{i}}\right)$, which indicates the effect of the fault on the voltage generated on the load. Eq. (2) shows the calculation of $D_{\mathrm{i}}$.

$D_{\mathrm{i}}=H_{0}-H_{1}$

Tab. 1 demonstrates the distortion index values in simulation while Tab. 2 shows the distortion index values in experimentation.

Table 1 The distortion index values of $\mathrm{i} 11$ and $\mathrm{i} 12$ faults for simulation

\begin{tabular}{|c|c|c|c|}
\hline $\begin{array}{c}\text { Distortion and } \\
\text { frequency orders }\end{array}$ & $H_{0}$ & $H_{1}$ & $D_{\mathrm{i}}$ \\
\hline $0 \mathrm{~Hz}$ (DC): & $0.08 \%$ & $1.27 \%$ & $-1.19 \%$ \\
\hline $80 \mathrm{~Hz}$ (Fnd): & $100.00 \%$ & $100.00 \%$ & 0 \\
\hline $160 \mathrm{~Hz}$ (h2): & $0.33 \%$ & $2.44 \%$ & $-2.11 \%$ \\
\hline $240 \mathrm{~Hz}$ (h3): & $0.73 \%$ & $1.93 \%$ & $-1.20 \%$ \\
\hline $320 \mathrm{~Hz}$ (h4): & $0.44 \%$ & $2.02 \%$ & $-1.62 \%$ \\
\hline $400 \mathrm{~Hz}$ (h5): & $0.49 \%$ & $2.07 \%$ & $-1.56 \%$ \\
\hline $480 \mathrm{~Hz}$ (h6): & $0.31 \%$ & $1.13 \%$ & $-0.82 \%$ \\
\hline $560 \mathrm{~Hz}$ (h7): & $1.11 \%$ & $3.11 \%$ & $-2 \%$ \\
\hline $640 \mathrm{~Hz}$ (h8): & $0.11 \%$ & $0.16 \%$ & $+0.04 \%$ \\
\hline $720 \mathrm{~Hz}$ (h9): & $0.34 \%$ & $1.53 \%$ & $-1.21 \%$ \\
\hline $800 \mathrm{~Hz}(\mathrm{~h} 10):$ & $0.34 \%$ & $0.05 \%$ & $-0.71 \%$ \\
\hline $880 \mathrm{~Hz}(\mathrm{~h} 11):$ & $0.97 \%$ & $0.60 \%$ & $+0.37 \%$ \\
\hline $960 \mathrm{~Hz}(\mathrm{~h} 12):$ & $0.47 \%$ & $1.55 \%$ & $-1.08 \%$ \\
\hline
\end{tabular}


Table 2 The distortion index values of i11 and i12 faults for experimentation

\begin{tabular}{|c|c|c|c|}
\hline $\begin{array}{c}\text { Distortion and } \\
\text { frequency orders }\end{array}$ & $H_{0}$ & $H_{1}$ & $D_{\mathrm{i}}$ \\
\hline $0 \mathrm{~Hz}$ (DC): & $0.012 \%$ & $1.37 \%$ & $-1.23 \%$ \\
\hline $80 \mathrm{~Hz}$ (Fnd): & $100.00 \%$ & $100.00 \%$ & 0 \\
\hline $160 \mathrm{~Hz}(\mathrm{~h} 2):$ & $0.30 \%$ & $2.3 * \%$ & $-2.01 \%$ \\
\hline $240 \mathrm{~Hz}(\mathrm{~h} 3):$ & $0.63 \%$ & $1.82 \%$ & $-1.18 \%$ \\
\hline $320 \mathrm{~Hz}(\mathrm{~h} 4):$ & $0.54 \%$ & $2.02 \%$ & $-1.52 \%$ \\
\hline $400 \mathrm{~Hz}(\mathrm{~h} 5):$ & $0.49 \%$ & $2.07 \%$ & $-1.56 \%$ \\
\hline $480 \mathrm{~Hz}(\mathrm{~h} 6):$ & $0.31 \%$ & $1.1 \%$ & $-0.79 \%$ \\
\hline $560 \mathrm{~Hz}(\mathrm{~h} 7):$ & $1.16 \%$ & $3.11 \%$ & $-1.9 \%$ \\
\hline $640 \mathrm{~Hz}$ (h8): & $0.11 \%$ & $0.17 \%$ & $+0.05 \%$ \\
\hline $720 \mathrm{~Hz}$ (h9): & $0.34 \%$ & $1.56 \%$ & $-1.24 \%$ \\
\hline $800 \mathrm{~Hz}(\mathrm{~h} 10):$ & $0.34 \%$ & $0.09 \%$ & $-0.75 \%$ \\
\hline $880 \mathrm{~Hz}(\mathrm{~h} 11):$ & $0.97 \%$ & $0.60 \%$ & $+0.37 \%$ \\
\hline $960 \mathrm{~Hz}(\mathrm{~h} 12):$ & $0.43 \%$ & $1.55 \%$ & $-1.04 \%$ \\
\hline
\end{tabular}

Experimental results support the simulation results. According to the results, Fig. 4 shows the distortion index curve for faults of I1 1 and I12.

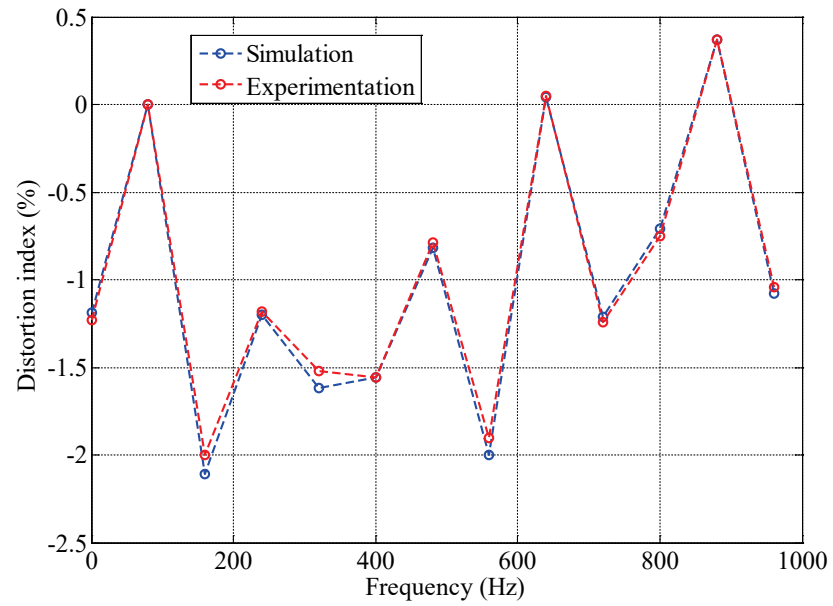

Figure 4 The distortion index curve of I11 and I12 faults

The curve in Fig. 4 and values in Tab. 1 and Tab. 2 demonstrate that the distortions in the generated voltage are a negative direction. This indicates that there is an error on this circuit. The distortions at $880 \mathrm{~Hz}$ and $640 \mathrm{~Hz}$ on the voltage are not caused by the fault but the distortions at the other frequency values are caused by the defects. The distortions caused by non-operation of I11 and I12 take their maximum values at $160 \mathrm{~Hz}$ and $560 \mathrm{~Hz}$. Eq. (3) shows how to find the voltage value of the distortion $\left(U_{\mathrm{d}}\right)$.

$U_{\mathrm{d}}=\frac{D_{\mathrm{i}} \times U_{\mathrm{m}}}{100}$

Eqs. (4) and (5) give the voltage value of the distortion at $160 \mathrm{~Hz}$ and $560 \mathrm{~Hz}$.

$$
\begin{aligned}
& U_{\mathrm{d}, 160}=\frac{2.01 \times 170}{100} \\
& U_{\mathrm{d}, 560}=\frac{1.9 \times 170}{100}
\end{aligned}
$$

If faults occur in switches I1, I2, I11 and I12; the alternating voltage on the load will be as shown in Fig. 5a and $5 \mathrm{~b}$. Fig. $5 \mathrm{c}$ shows the pulse width modulations controlling these switches.
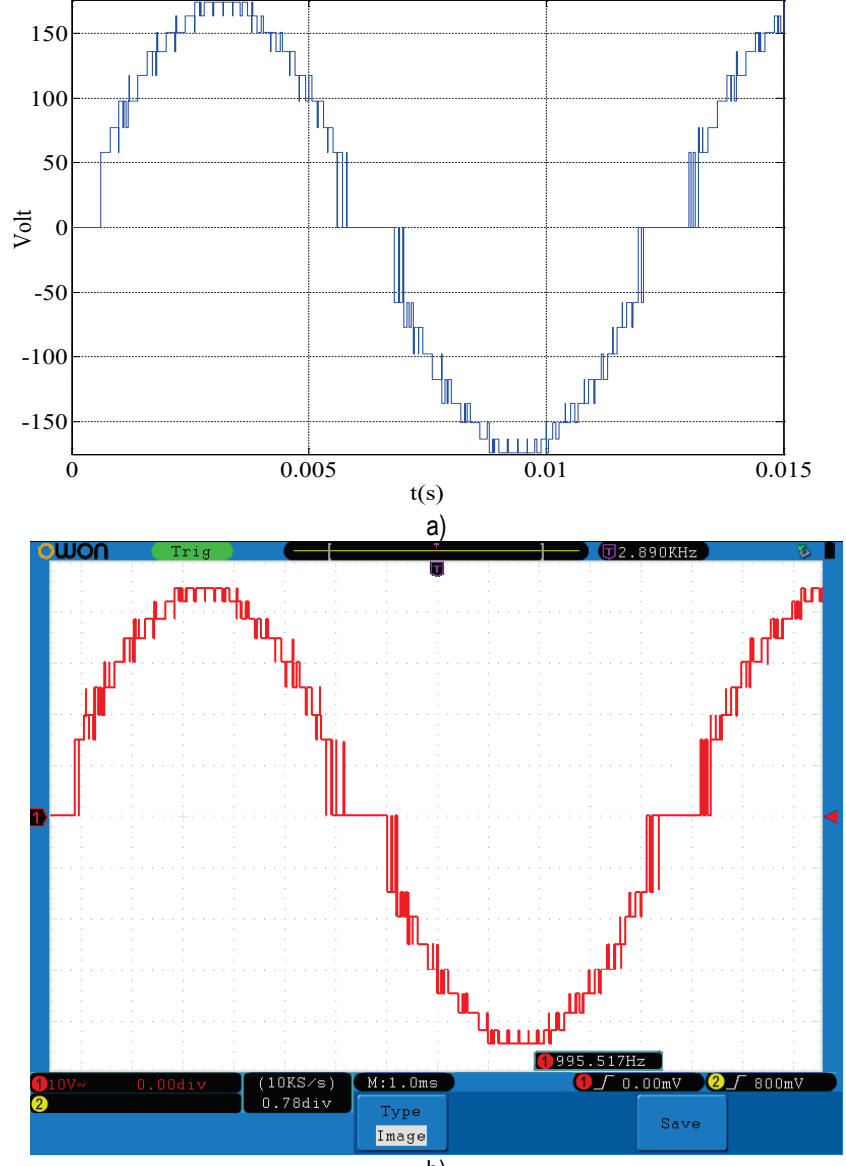

b)
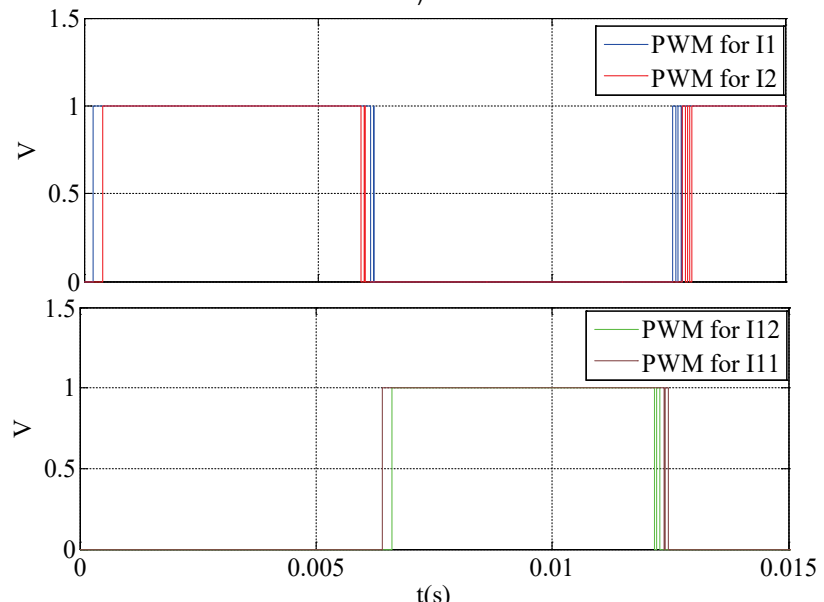

c)

Figure 5 Alternating voltage for fault of I1, I2, I11 and I12: a) simulation, b) experimentation, c) The pulse width modulations controlling I1, I2, I11 and I12

The fault of the switches on the positive and negative sides of the voltage cause the generation of constant voltage as two source voltages. This shifts the desired clean sinus wave voltage to $\alpha_{1}$. Eq. (6) shows the alternating voltage equation.

$U(t)=2 U+8 U \cdot \sin \left(\omega t+\alpha_{1}\right)$

Tab. 3 and Tab. 4 demonstrate the distortion index values in simulation and experimentation while Fig. 6 shows the distortion index curve for faults of I1, I2, I1 1 and I12. The results in Tab. 4 validate the results in Tab. 3 
Table 3 Demonstrations of the distortion index values for simulation

\begin{tabular}{|c|c|c|c|}
\hline $\begin{array}{c}\text { Distortion and } \\
\text { frequency orders }\end{array}$ & $H_{0}$ & $H_{1}$ & $D_{\mathrm{i}}$ \\
\hline $0 \mathrm{~Hz}$ (DC): & $0.08 \%$ & $1.27 \%$ & $-1.21 \%$ \\
\hline $80 \mathrm{~Hz}$ (Fnd): & $100.00 \%$ & $100.00 \%$ & $0 \%$ \\
\hline $160 \mathrm{~Hz}$ (h2): & $0.33 \%$ & $2.44 \%$ & $-2.11 \%$ \\
\hline $240 \mathrm{~Hz}$ (h3): & $0.73 \%$ & $1.93 \%$ & $-1.23 \%$ \\
\hline $320 \mathrm{~Hz}$ (h4): & $0.44 \%$ & $2.02 \%$ & $-1.62 \%$ \\
\hline $400 \mathrm{~Hz}$ (h5): & $0.49 \%$ & $2.07 \%$ & $-1.58 \%$ \\
\hline $480 \mathrm{~Hz}$ (h6): & $0.31 \%$ & $1.13 \%$ & $-0.82 \%$ \\
\hline $560 \mathrm{~Hz}$ (h7): & $1.11 \%$ & $3.11 \%$ & $-2 \%$ \\
\hline $640 \mathrm{~Hz}$ (h8): & $0.11 \%$ & $0.28 \%$ & $-0.17 \%$ \\
\hline $720 \mathrm{~Hz}$ (h9): & $0.34 \%$ & $1.53 \%$ & $-1.21 \%$ \\
\hline $800 \mathrm{~Hz}$ (h10): & $0.34 \%$ & $0.05 \%$ & $+0.29 \%$ \\
\hline $880 \mathrm{~Hz}$ (h11): & $0.97 \%$ & $0.60 \%$ & $+0.37 \%$ \\
\hline $960 \mathrm{~Hz}$ (h12): & $0.47 \%$ & $1.55 \%$ & $-1.08 \%$ \\
\hline
\end{tabular}

Table 4 Demonstrations of the distortion index values for experimentation

\begin{tabular}{|c|c|c|c|}
\hline $\begin{array}{c}\text { Distortion and } \\
\text { frequency orders }\end{array}$ & $H_{0}$ & $H_{1}$ & $D_{\mathrm{i}}$ \\
\hline $0 \mathrm{~Hz}$ (DC): & $0.08 \%$ & $1.16 \%$ & $-1.08 \%$ \\
\hline $80 \mathrm{~Hz}$ (Fnd): & $100.00 \%$ & $100.00 \%$ & $0 \%$ \\
\hline $160 \mathrm{~Hz}$ (h2): & $0.44 \%$ & $2.44 \%$ & $-2.00 \%$ \\
\hline $240 \mathrm{~Hz}$ (h3): & $0.93 \%$ & $1.83 \%$ & $-0.9 \%$ \\
\hline $320 \mathrm{~Hz}$ (h4): & $0.54 \%$ & $2.02 \%$ & $-1.52 \%$ \\
\hline $400 \mathrm{~Hz}$ (h5): & $0.45 \%$ & $2.1 \%$ & $-1.65 \%$ \\
\hline $480 \mathrm{~Hz}$ (h6): & $0.31 \%$ & $1.11 \%$ & $-0.80 \%$ \\
\hline $560 \mathrm{~Hz}$ (h7): & $1.21 \%$ & $3.11 \%$ & $-1.98 \%$ \\
\hline $640 \mathrm{~Hz}$ (h8): & $0.11 \%$ & $0.26 \%$ & $-0.15 \%$ \\
\hline $720 \mathrm{~Hz}$ (h9): & $0.34 \%$ & $1.73 \%$ & $-1.41 \%$ \\
\hline $800 \mathrm{~Hz}$ (h10): & $0.34 \%$ & $0.15 \%$ & $+0.19 \%$ \\
\hline $880 \mathrm{~Hz}$ (h11): & $0.99 \%$ & $0.50 \%$ & $+0.49 \%$ \\
\hline $960 \mathrm{~Hz}$ (h12): & $0.45 \%$ & $1.15 \%$ & $-0.70 \%$ \\
\hline
\end{tabular}

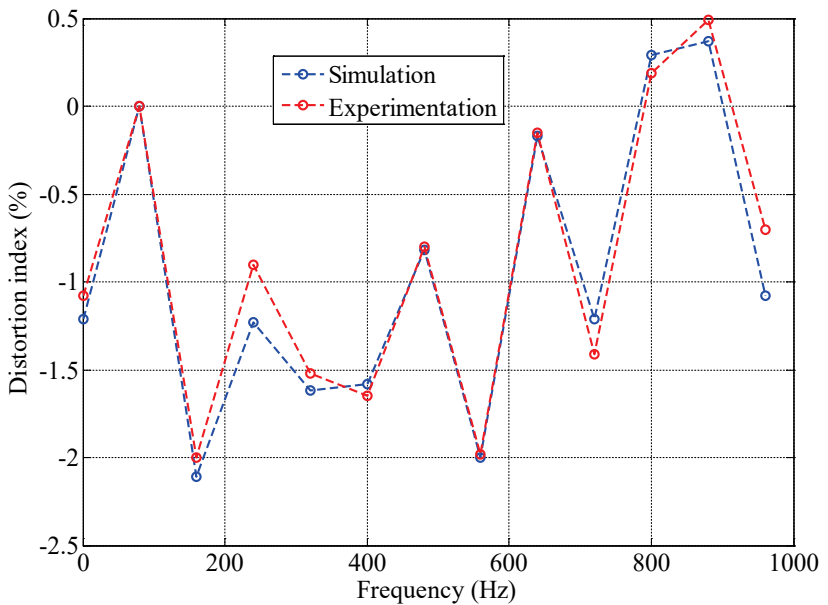

Figure 6 The distortion index of curve of I1, I2, I11 and I12 in the simulation, and the experimentation

The curve in Fig. 6, the values in Tab. 3, and Tab. 4 show that the distortions in the generated voltage are negative, indicating that there is an error on this circuit. The distortions at $320 \mathrm{~Hz}$ and $480 \mathrm{~Hz}$ on the voltage are not caused by the fault but the distortions at the other frequency values are caused by the defects. The distortions caused by non-operation of I1, I2, I11 and I12 are their maximum values at $240 \mathrm{~Hz}, 400 \mathrm{~Hz}, 560 \mathrm{~Hz}$ and $720 \mathrm{~Hz}$. Eqs. (7) (10) give the voltage value of the distortion at $240 \mathrm{~Hz}, 400$ $\mathrm{Hz}, 560$ and $\mathrm{Hz} 720 \mathrm{~Hz}$.

$$
\begin{aligned}
& U_{\mathrm{d}, 240}=\frac{1.23 \times 170}{100} \\
& U_{\mathrm{d}, 400}=\frac{1.58 \times 170}{100}
\end{aligned}
$$

$$
\begin{aligned}
& U_{\mathrm{d}, 560}=\frac{2 \times 170}{100} \\
& U_{\mathrm{d}, 720}=\frac{1.21 \times 170}{100}
\end{aligned}
$$

With the above calculations, the distortion voltages obtained at different frequencies are shown in Fig. 7.

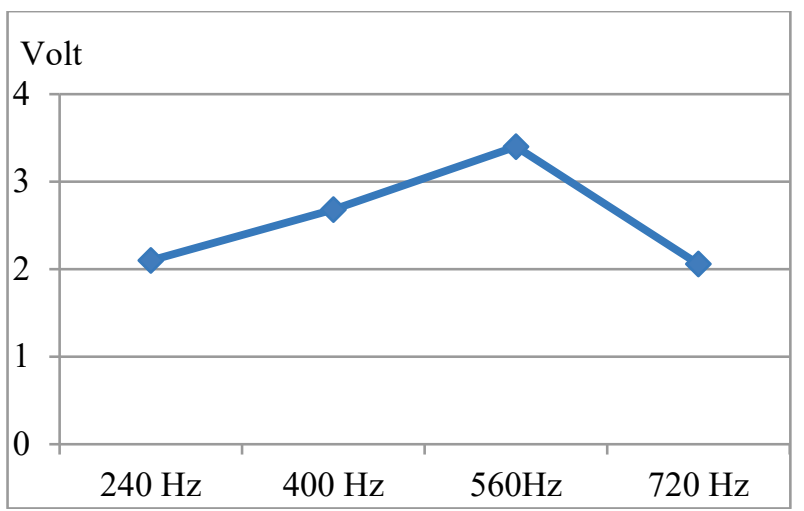

Figure 7 The distortion voltages for non-operation of I1, I2, I11 and I12

If the I1, I2, I11, and I12 switches do not work, a distortion of $2.1 \mathrm{~V}$, a distortion of $2.68 \mathrm{~V}$, a distortion of $3.4 \mathrm{~V}$ and a distortion of $2.058 \mathrm{~V}$ occur at frequencies of $240 \mathrm{~Hz}, 400 \mathrm{~Hz}, 560 \mathrm{~Hz}$ and $720 \mathrm{~Hz}$ in consecutive.

While faults occur in switches I19 and I20, the alternating voltage on the load is as shown in Fig. 8.
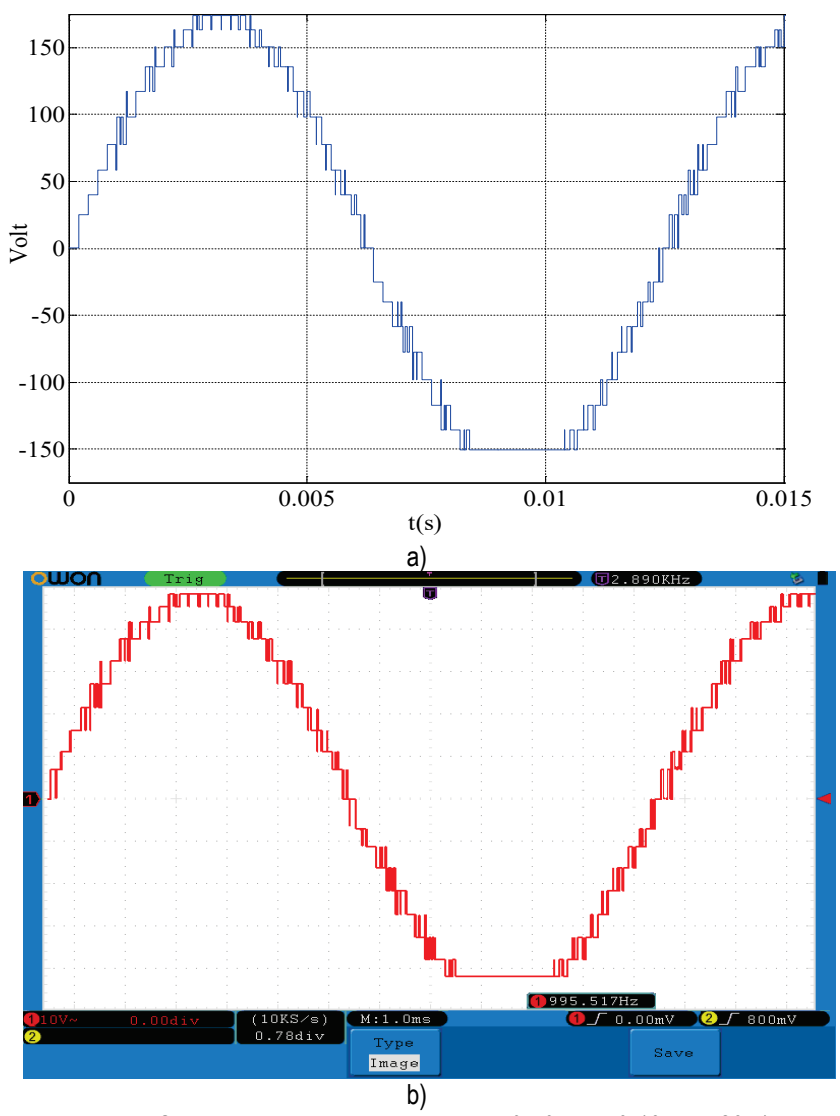

Figure 8 Showing the distortion index curve for faults of I19 and I20 a) simulation, b) experimentation

The effective value for the negative side of the voltage is like Eq. (11). 
$U(t)=10 U \cdot \sin (\omega t)-2 U \cdot \sin \left(\omega t+\alpha_{2}\right)$

Tab. 4 and Tab. 6 demonstrate the distortion index values while Fig. 9 shows the distortion index curve for faults of I19 and I20.

Table 5 The distortion index values for simulation

\begin{tabular}{|c|c|c|c|}
\hline $\begin{array}{c}\text { Distortion and } \\
\text { frequency orders }\end{array}$ & $H_{0}$ & $H_{1}$ & $D_{\mathrm{i}}$ \\
\hline $0 \mathrm{~Hz}$ (DC): & $0.08 \%$ & $1.42 \%$ & $-1.36 \%$ \\
\hline $80 \mathrm{~Hz}$ (Fnd): & $100.00 \%$ & $100.00 \%$ & $0 \%$ \\
\hline $160 \mathrm{~Hz}$ (h2): & $0.33 \%$ & $2.99 \%$ & $-2.66 \%$ \\
\hline $240 \mathrm{~Hz}$ (h3): & $0.73 \%$ & $1.83 \%$ & $-1.1 \%$ \\
\hline $320 \mathrm{~Hz}$ (h4): & $0.44 \%$ & $1.62 \%$ & $-1.28 \%$ \\
\hline $400 \mathrm{~Hz}$ (h5): & $0.49 \%$ & $1.84 \%$ & $-1.35 \%$ \\
\hline $480 \mathrm{~Hz}$ (h6): & $0.31 \%$ & $1.46 \%$ & $-1.15 \%$ \\
\hline $560 \mathrm{~Hz}$ (h7): & $1.11 \%$ & $0.49 \%$ & $+0.62 \%$ \\
\hline $640 \mathrm{~Hz}$ (h8): & $0.11 \%$ & $0.39 \%$ & $-0.28 \%$ \\
\hline $720 \mathrm{~Hz}$ (h9): & $0.34 \%$ & $0.30 \%$ & $+0.04 \%$ \\
\hline $800 \mathrm{~Hz}$ (h10): & $0.34 \%$ & $0.50 \%$ & $-0.16 \%$ \\
\hline $880 \mathrm{~Hz}(\mathrm{~h} 11):$ & $0.97 \%$ & $0.74 \%$ & $-0.23 \%$ \\
\hline $960 \mathrm{~Hz}(\mathrm{~h} 12):$ & $0.47 \%$ & $0.32 \%$ & $-0.15 \%$ \\
\hline
\end{tabular}

Table 6 The distortion index values for experimentation

\begin{tabular}{|c|c|c|c|}
\hline $\begin{array}{c}\text { Distortion and } \\
\text { frequency orders }\end{array}$ & $H_{0}$ & $H_{1}$ & $D_{\mathrm{i}}$ \\
\hline $0 \mathrm{~Hz}$ (DC): & $0.20 \%$ & $1.42 \%$ & $-1.32 \%$ \\
\hline $80 \mathrm{~Hz}$ (Fnd): & $100.00 \%$ & $100.00 \%$ & $0 \%$ \\
\hline $160 \mathrm{~Hz}$ (h2): & $0.49 \%$ & $2.99 \%$ & $-2.50 \%$ \\
\hline $240 \mathrm{~Hz}$ (h3): & $0.86 \%$ & $1.83 \%$ & $-0.97 \%$ \\
\hline $320 \mathrm{~Hz}$ (h4): & $0.34 \%$ & $1.62 \%$ & $-1.38 \%$ \\
\hline $400 \mathrm{~Hz}(\mathrm{~h} 5):$ & $0.4 \%$ & $1.84 \%$ & $-1.44 \%$ \\
\hline $480 \mathrm{~Hz}(\mathrm{~h} 6):$ & $0.31 \%$ & $1.4 \%$ & $-1.09 \%$ \\
\hline $560 \mathrm{~Hz}$ (h7): & $1.11 \%$ & $0.39 \%$ & $+0.72 \%$ \\
\hline $640 \mathrm{~Hz}$ (h8): & $0.11 \%$ & $0.39 \%$ & $-0.28 \%$ \\
\hline $720 \mathrm{~Hz}$ (h9): & $0.44 \%$ & $0.30 \%$ & $+0.14 \%$ \\
\hline $800 \mathrm{~Hz}(\mathrm{~h} 10):$ & $0.24 \%$ & $0.45 \%$ & $-0.21 \%$ \\
\hline $880 \mathrm{~Hz}(\mathrm{~h} 11):$ & $0.97 \%$ & $0.71 \%$ & $-0.26 \%$ \\
\hline $960 \mathrm{~Hz}(\mathrm{~h} 12):$ & $0.47 \%$ & $0.30 \%$ & $-0.17 \%$ \\
\hline
\end{tabular}

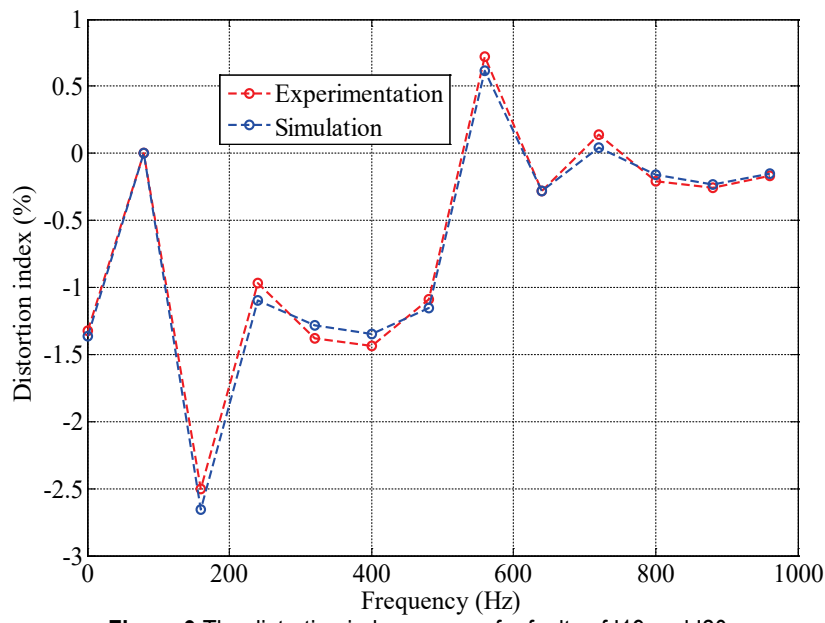

Figure 9 The distortion indexes curve for faults of I19 and I20

Values of the distortions in the generated voltage are negative in Fig. 9, in Tab. 5, and Tab. 6, indicating that there is an error on this circuit. The distortions at $720 \mathrm{~Hz}$ and $560 \mathrm{~Hz}$ on the voltage are not caused by the fault but the distortions at the other frequency values are caused by the defects. The distortions caused by non-operation of I19 and $\mathrm{I} 20$ are their maximum values at $0 \mathrm{~Hz}, 160 \mathrm{~Hz}, 400 \mathrm{~Hz}$ and $480 \mathrm{~Hz}$. Eqs. (12) - (15) give the voltage value of the distortion at $240 \mathrm{~Hz}, 400 \mathrm{~Hz}$ and $560 \mathrm{~Hz}$.
$U_{\mathrm{d}, 0}=\frac{1.32 \times 170}{100}$

$U_{\mathrm{d}, 160}=\frac{2.50 \times 170}{100}$

$U_{\mathrm{d}, 400}=\frac{1.44 \times 170}{100}$

$U_{\mathrm{d}, 480}=\frac{1.09 \times 170}{100}$

With the above calculations, the distortion voltages obtained at different frequencies are shown in Fig. 10.

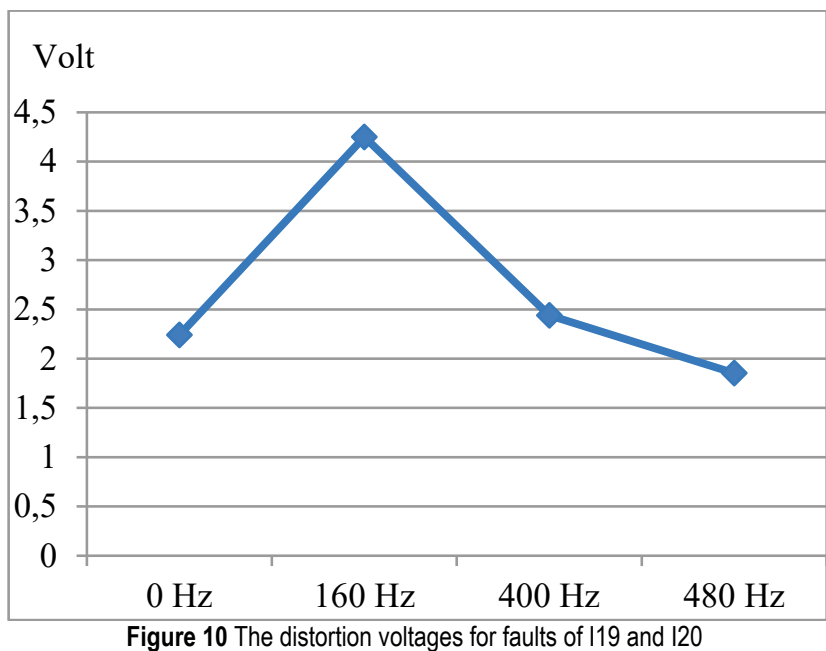

$2.24 \mathrm{~V}$ of the distortion is occurring at $0 \mathrm{~Hz}$, when $4.25 \mathrm{~V}$ of the distortion is occurring at $160 \mathrm{~Hz}$. after that, the faults of I19 and I20 cause successive $2.44 \mathrm{~V}$ of the distortion and $1.853 \mathrm{~V}$ of the distortion at the $400 \mathrm{~Hz}$ and $480 \mathrm{~Hz}$.

If faults occur in switches I3, I4, I19 and I20; the alternating voltage on the load forms as shown in Fig. 11a, and $11 \mathrm{~b}$. Fig. $11 \mathrm{c}$ shows the pulse width modulations controlling these switches.

The fault of I3, I4, I19 and I20 causes the two sides of the positive and negative parts of the alternating voltage to disappear. This disrupts the alternating voltage structure and its effective value.

Tab. 7 and Tab. 8 demonstrate the distortion index values in simulation and experimentation while Fig. 12 shows the distortion index curves for faults of I3, I4, I19 and $\mathrm{I} 20$.

The curve in Fig. 12, the values in Tab. 7 and Tab. 8 because the distortions in the generated voltage are in negative direction, there is an error on this circuit. The distortions at $880 \mathrm{~Hz}$ and $960 \mathrm{~Hz}$ on the voltage are not caused by the fault but the distortions at the other frequency values are caused by the defects. The distortions caused by non-operation of I3, I4, I19 and I20 are their maximum values at $160 \mathrm{~Hz}, 320 \mathrm{~Hz}, 560 \mathrm{~Hz}, 640 \mathrm{~Hz}$ and $800 \mathrm{~Hz}$. Eqs. (16) - (20) give the voltage value of the distortion for the frequencies.

$U_{\mathrm{d}, 160}=\frac{4.58 \times 170}{100}$ 


$$
\begin{aligned}
& U_{\mathrm{d}, 320}=\frac{2.09 \times 170}{100} \\
& U_{\mathrm{d}, 560}=\frac{1.15 \times 170}{100} \\
& U_{\mathrm{d}, 640}=\frac{1.83 \times 170}{100} \\
& U_{\mathrm{d}, 800}=\frac{1.97 \times 170}{100}
\end{aligned}
$$
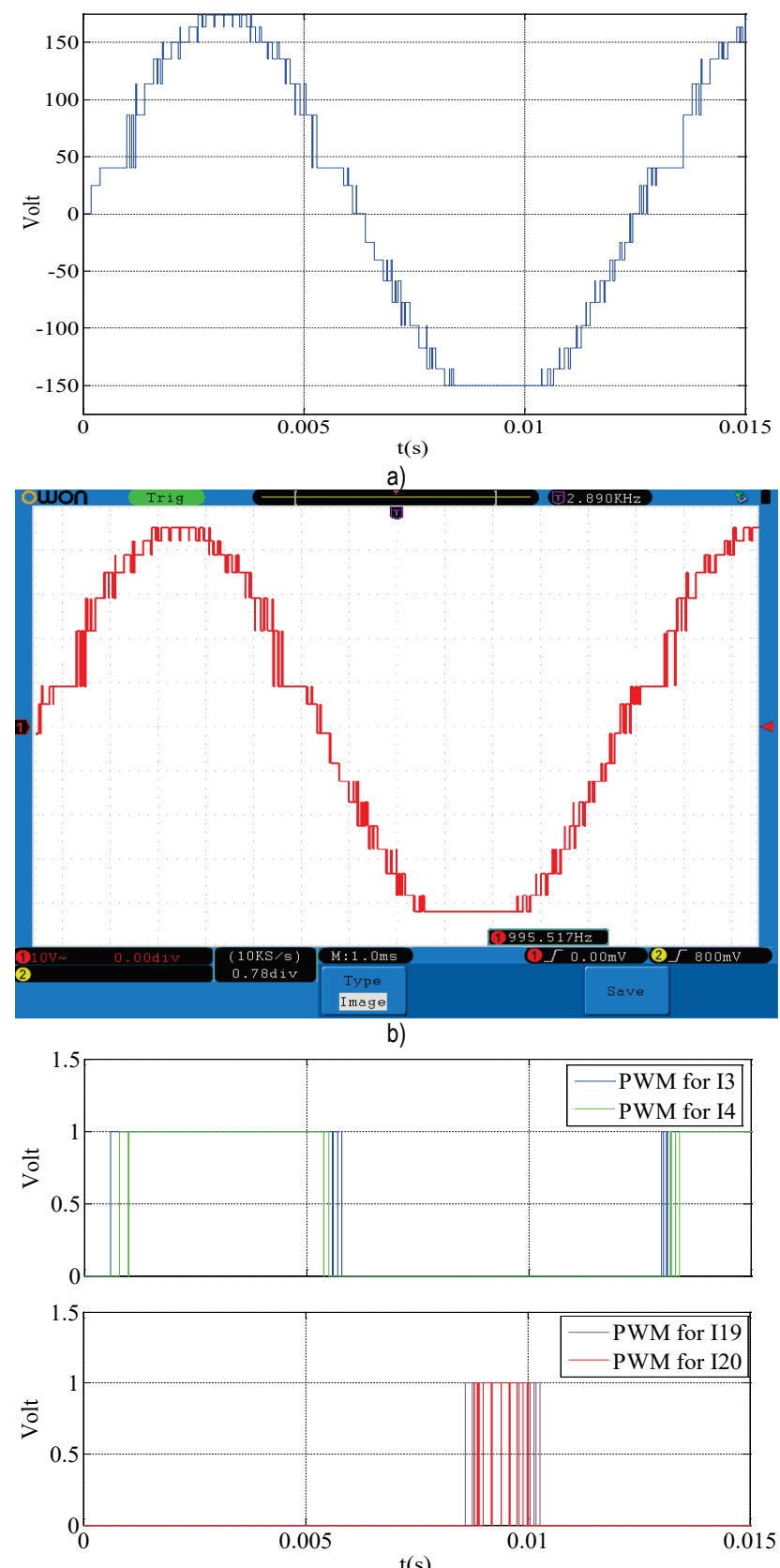

c)

Figure 11 Alternating voltage for fault of $I 3,14$, I19 and I20 a) simulation, b) experimentation c) the pulse width modulations controlling I3, I4, I19 and I20

With the above calculations, the distortion voltages obtained at different frequencies are shown in Fig. 13.

If I3, I4, I19 and I20 do not work, a distortion of 7.86 $\mathrm{V}$ occurs at $160 \mathrm{~Hz}$, while a distortion of $3.89 \mathrm{~V}$ occurs at $320 \mathrm{~Hz}$. These defective switches also cause respectively distortion of $1.955 \mathrm{~V}, 3.11 \mathrm{~V}$, and $3.35 \mathrm{~V}$ at $560 \mathrm{~Hz}, 640$ $\mathrm{Hz}$ and $800 \mathrm{~Hz}$.
Table 7 The distortion index values for faults of I3, I4, I19 and 120 .

\begin{tabular}{|c|c|c|c|}
\hline $\begin{array}{c}\text { Distortion and } \\
\text { frequency orders }\end{array}$ & $H_{0}$ & $H_{1}$ & $D_{\mathrm{i}}$ \\
\hline $0 \mathrm{~Hz}$ (DC): & $0.08 \%$ & $0.20 \%$ & $-0.16 \%$ \\
\hline $80 \mathrm{~Hz}$ (Fnd): & $100.00 \%$ & $100 \%$ & $0 \%$ \\
\hline $160 \mathrm{~Hz}$ (h2): & $0.33 \%$ & $4.91 \%$ & $-4.58 \%$ \\
\hline $240 \mathrm{~Hz}$ (h3): & $0.73 \%$ & $1.29 \%$ & $-0.56 \%$ \\
\hline $320 \mathrm{~Hz}$ (h4): & $0.44 \%$ & $2.53 \%$ & $-2.09 \%$ \\
\hline $400 \mathrm{~Hz}$ (h5): & $0.49 \%$ & $0.94 \%$ & $-0.45 \%$ \\
\hline $480 \mathrm{~Hz}$ (h6): & $0.31 \%$ & $0.34 \%$ & $-0.03 \%$ \\
\hline $560 \mathrm{~Hz}$ (h7): & $1.11 \%$ & $2.26 \%$ & $-1.15 \%$ \\
\hline $640 \mathrm{~Hz}$ (h8): & $0.11 \%$ & $1.94 \%$ & $-1.83 \%$ \\
\hline $720 \mathrm{~Hz}$ (h9): & $0.34 \%$ & $0.81 \%$ & $-0.47 \%$ \\
\hline $800 \mathrm{~Hz}$ (h10): & $0.34 \%$ & $2.31 \%$ & $-1.97 \%$ \\
\hline $880 \mathrm{~Hz}(\mathrm{~h} 11):$ & $0.97 \%$ & $0.85 \%$ & $+0.12 \%$ \\
\hline $960 \mathrm{~Hz}$ (h12): & $0.47 \%$ & $0.20 \%$ & $+0.27 \%$ \\
\hline
\end{tabular}

Table 8 The distortion index values for faults of 13 , I4, I19 and I20.for experimentation

\begin{tabular}{|c|c|c|c|}
\hline $\begin{array}{c}\text { Distortion and } \\
\text { frequency orders }\end{array}$ & $H_{0}$ & $H_{1}$ & $D_{\mathrm{i}}$ \\
\hline $0 \mathrm{~Hz}$ (DC): & $0.08 \%$ & $0.10 \%$ & $-0.06 \%$ \\
\hline $80 \mathrm{~Hz}$ (Fnd): & $100.00 \%$ & $100 \%$ & $0 \%$ \\
\hline $160 \mathrm{~Hz}$ (h2): & $0.39 \%$ & $4.91 \%$ & $-4.52 \%$ \\
\hline $240 \mathrm{~Hz}$ (h3): & $0.83 \%$ & $1.29 \%$ & $-0.66 \%$ \\
\hline $320 \mathrm{~Hz}$ (h4): & $0.40 \%$ & $2.53 \%$ & $-2.13 \%$ \\
\hline $400 \mathrm{~Hz}$ (h5): & $0.41 \%$ & $0.94 \%$ & $-0.53 \%$ \\
\hline $480 \mathrm{~Hz}$ (h6): & $0.31 \%$ & $0.31 \%$ & $-0.00 \%$ \\
\hline $560 \mathrm{~Hz}$ (h7): & $1.11 \%$ & $2.06 \%$ & $-0.95 \%$ \\
\hline $640 \mathrm{~Hz}$ (h8): & $0.21 \%$ & $1.94 \%$ & $-1.73 \%$ \\
\hline $720 \mathrm{~Hz}$ (h9): & $0.34 \%$ & $0.85 \%$ & $-0.51 \%$ \\
\hline $800 \mathrm{~Hz}(\mathrm{~h} 10):$ & $0.34 \%$ & $2.24 \%$ & $-1.90 \%$ \\
\hline $880 \mathrm{~Hz}$ (h11): & $0.9 \%$ & $0.85 \%$ & $+0.05 \%$ \\
\hline $960 \mathrm{~Hz}(\mathrm{~h} 12):$ & $0.41 \%$ & $0.20 \%$ & $+0.21 \%$ \\
\hline
\end{tabular}

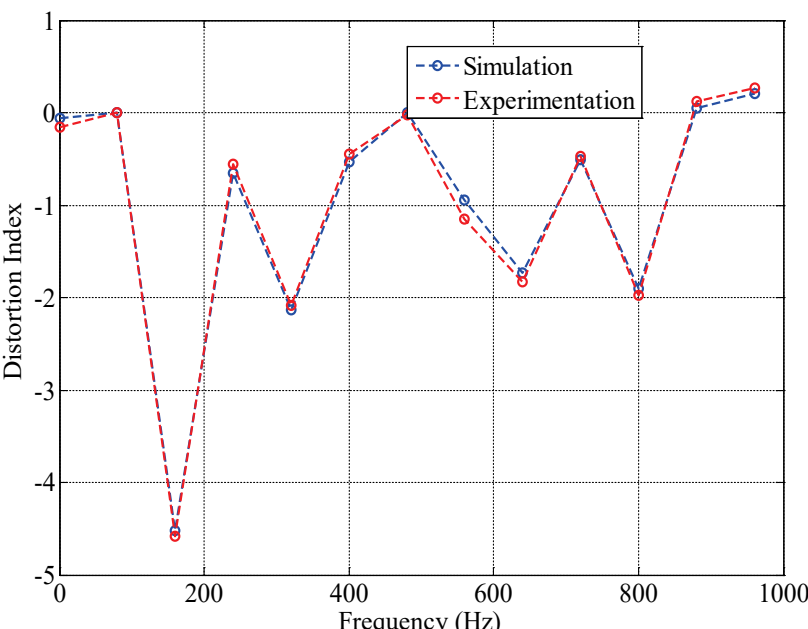

Figure 12 The distortion index curves for faults of I3, I4, I19 and I20 in the simulation, and the experimentation

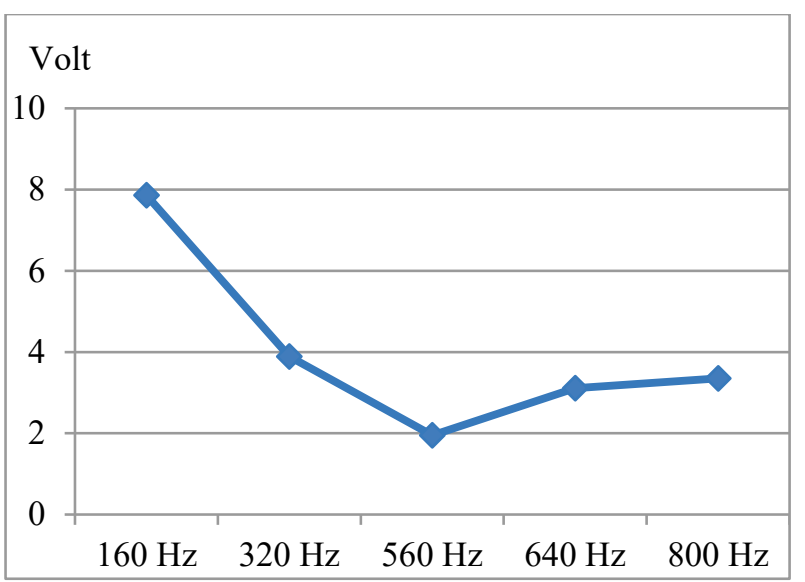

Figure 13 The distortion voltages for faults of $\mathrm{I} 19$ and $\mathrm{I} 20$ 


\section{CONCLUSIONS}

In this study, faults that can occur in a 21-level inverter have been determined with a new method. The faults occurring in different situations on the device are investigated. According to the method, the fault effect on the voltages of the load is revealed after the creating distortion index that is formed by the difference between the harmonic distortion of the references alternating voltage, and the harmonic distortion of the alternating voltage with fault. Because of this, the distortion index curves and tables are designed for each fault condition and the fault condition map is formed. There may be a large number of possible fault conditions. However, the deterioration index curve, which gives information on what the deterioration tendencies are in the event of fault, is obtained for several different situations. The direction of the curves is negative, according to the current position of the element in which the fault occurs. Although the curves show similarities in the case of failure, all of the curves are different. According to this, the directions in the curves are positive when the fault does not arise. If the directions in the curves are negative then the fault arises. So, the curve can inform about areas on the device in order to find fault. In this case, the detection of the faults occurring in a device with a very complex switches structure is facilitated. Then, unnecessary deformation can decrease in the device. Therefore, time and financial savings are made.

\section{REFERENCES}

[1] Abushnaf, J. \& Rassau, A. (2018). Impact of energy management system on the sizing of a grid-connected PV/Battery system. The Electricity Journal, 31(2), 58-66. https://doi.org/10.1016/j.tej.2018.02.009

[2] Erol, C. \& Sayan, H. H. (2016). SSPWM Three Phase Inverter Design and Experimented on Unbalanced Loads. Tehnički vjesnik, 23(5), 1239-1244. https://doi.org/10.17559/TV-20150730222021

[3] Özbay, H., Öncüb, S., \& Kesler, M. (2017). SMC-DPC based active and reactive power control of grid-tied three phase inverter for PV systems. International Journal of Hydrogen Energy, 42(28), 17713-17722. https://doi.org/10.1016/j.ijhydene.2017.04.020

[4] Ozturk, N., Canbaz, R., \& Çelik, E. (2012). Constant voltage constant frequency control for single phase three level inverter. 2012 International Conference on Renewable Energy Research and Applications (ICRERA), 1-5. https://doi.org/10.1109/ICRERA.2012.6477332

[5] Raghava Reddy, K., Mahesh, M., \& Vijaya Kumar, M. (2017). Simulation of H6 full bridge Inverter for grid connected PV system using SPWM technique. International Research Journal of Engineering and Technology (IRJET), 4(1), 1451-1457.

[6] Akar, M. \& Gercekcioglu, S. H. (2017). Instantaneous power factor signature analysis for efficient fault diagnosis in inverter fed three phased induction motors. International Journal of Hydrogen Energy, 42(12), 8338-8345. https://doi.org/10.1016/j.jijhydene.2017.02.151

[7] Kerem, A., Aksoz, A., Saygin, A., \& Yilmaz, E. N. (2017). Smart grid integration of micro hybrid power system using 6-switched 3-level inverter. In IEEE Smart Grid and Cities Congress and Fair (ICSG), $20175^{\text {th }}$ International Istanbul, 161-165. https://doi.org/10.1109/SGCF.2017.7947625

[8] Trabelsi, M., Boussak, M., \& Benbouzid, M. (2017). Multiple criteria for high performance real-time diagnostic of single and multiple open-switch faults in ac-motor drives: Application to IGBT-based voltage source inverter. Electric Power Systems Research, 144, 136-149. https://doi.org/10.1016/j.epsr.2016.11.021

[9] Livadaru, L., Simion, A., Munteanu, A., Cojan, M., \& Dabija, O. (2013). Dual Cage High Power Induction Motor with Direct Start-up. Design and FEM Analysis. Advances in Electrical and Computer Engineering, 13(2), 55-58. https://doi.org/10.4316/AECE.2013.02009

[10] Chose, G. \& Park, M. (1989). An Improved PWM Technique for A. C. Chopper. IEEE Trans. on Power Electronics, 4 , 1496-1505.

[11] Su, G. J. (2006). Pulse-Width-Modulation Schemes for an Integrated Traction and Compressor Drive System. $21^{\text {st }}$ Applied Power Electronics Conference and Exposition (APEC'06), vol. 2, March 19-23, 640-645. https://doi.org/10.1109/APEC.2006.1620606

[12] Dileep, G., Singh, S. N., \& Singh, G. K. (2017). Modelling, design and stability analysis of an improved SEPIC converter for renewable energy systems. International Journal of Electronics, 104(9), 1527-1545. https://doi.org/10.1080/00207217.2017.1312709

[13] Raj, N., Jagadanand, G., \& George, S. (2016). A Modified Charge Balancing Scheme for Cascaded H-Bridge Multilevel Inverter. Journal of Power Electronics, 16(6), 2067-2075. https://doi.org/10.6113/JPE.2016.16.6.2067

[14] Gašparini, K., Nasser, A., \& Sladić, S. (2014). Fault tolerant LED power converter design for more efficient and durable lighting. Engineering Review, 34(3), 189-195.

[15] Zhu, S. \& Hu, B. (2016). Key technologies of active power filter for aircraft: a review. Engineering Review, 36(3), 221237.

Contact information:

Erol CAN, Assist. Prof. Dr.

School of Civil Aviation, Erzincan University,

Aircraft Airframe Power Plant,

Yanliz Bag Yerleşkesi, 24100 Erzincan, Turkey

can_e@hotmail.com 